УДК 532.5

\title{
ЯВИЩЕ ГІДРОДИНАМІЧНОЇ КАВІТАЦІЇ ЯК ДІЄВИЙ МЕХАНІЗМ ДИСПЕРГУВАННЯ ПРИ РЕАЛІЗАЦІЇ ДИСКРЕТНО-ІМПУЛЬСНОГО ВВЕДЕННЯ ЕНЕРГІЇ
}

\author{
Долінський А.А., академік НАН України, Авдсєва Л.Ю., д.т.Н., Жукотський Е.К., Макаренко А.А. \\ Інститут технічної теплофізики НАН Украӥни, вул. Желябова, 2а, м. Київ, 03680, Украӥна
}

Розглянуто вплив кавітаційних явищ на інтенсифікацію процесу диспергування при реалізації механізмів ДIВЕ. Розроблений та змонтований експериментальний стенд для дослідження впливу гідродинамічної кавітації на диспергування складних гетерогенних систем. Наведені результати експериментальних досліджень впливу теплофізичних режимів диспергування системи 3 фосфоліпідами на властивості утворених частинок.
Рассмотрено влияние кавитационных явлений на интенсификацию процесса диспергирования при реализации механизмов ДИВЭ. Разработан и смонтирован экспериментальный стенд для исследования влияния гидродинамической кавитации на диспергирование сложных гетерогенных систем. Приведены результаты экспериментальных исследований влияния теплофизических режимов диспергирования системы с фосфолипидами на свойства образованных частиц.
The cavitation's influence on the intensification of the dispersing process at the realization of mechanisms of DPEI are considered. Designed and installed an experimental stand for research of the influence of the hydrodynamic cavitation on dispersion of complex heterogeneous systems. Given results of experimental researches of influence of thermal modes of dispersion systems with phospholipids on the properties of formed particles.

Бібл. 9, рис. 4.

Ключові слова: гідродинамічна кавітація, фосфоліпіди, дискретно-імпульсне введення енергії.

Практично всі технології, які пов'язані 3 обробкою складних дисперсних систем, представляють собою сукупність декількох типових процесів: механічних, гідромеханічних, теплових, масобмінних і хімічних. Для диспергування та гомогенізації рідких дисперсних систем використовуються здебільшого гідромеханічні процеси $[1,2]$.

Інтенсифікація гідромеханічних, тепло- i массообмінних процесів в багатокомпонентних дисперсних системах здійснюється за рахунок підводу зовнішніх енергій. Енергія вводиться в апарат внаслідок механічного перемішування, енжектування потоків, ініціювання механічних вібрацій, використання відцентрових сил, акустичних або імпульсних впливів, потужних електричних розрядів та ін. [3].

Для досягнення мінімальних витрат енергії при диспергуванні необхідно перетворити введену енергію у форму коротких потужних імпульсів протягом короткого часу. Імпульсне введення енергії $\epsilon$ найбільш ефективним в процесах подрібнення дисперсної фази. При розробленні нових методів інтенсифікації технологічних процесів в гетерогенних системах і створенні енергоефективних апаратів для диспергування часова i просторова дискретизація введеної енергії є необхідною умовою.

Механізм дискретно-імпульсного введення енергії (ДІВЕ) представляє собою один із сучасних і найбільш перспективних підходів для інтенсифікації технологічних процесів диспергування в гетерогенних середовищах, оскільки забезпечує можливість раціонального і економного використання введеної в апарат енергії. На думку багатьох вчених саме кавітація є визначальним явищем при реалізації механізму ДІВЕ. За способом створення кавітація поділяється на гідродинамічну, парову i акустичну. В результаті розвитку кавітаційних явищ створюються умови для утворення в рідкій фазі дисперсної системи великої кількості газопарових бульбашок, що динамічно розвиваються i схлопуються. Ці бульбашки виконують роль 
локальних мікротрансформаторів, які перетворюють акумульовану в системі потенційну енергію в кінетичну енергію радіального руху рідини поблизу кожної бульбашки. Цей кумулятивний механізм дуже точно ілюструє принцип ДІВЕ: локалізації енергії в короткій часовій i в малих просторових областях і спрямуванні ударної дії концентрованої енергії у формі короткого імпульсу. Використання гідродинамічного методу генерації кавітації $\epsilon$ найменш енерговитратним і дозволяє провести перехід до збільшення продуктивності процесу за рахунок використання перспективної проточної системи обробки рідких матеріалів. В цьому випадку виникнення кавітації визначається різким зниженням тиску в потоці до значень, що відповідають тиску насичених парів оброблюваної рідини. При цьому утворюються ядра кавітації різних розмірів, що покращує розвиток кавітації та процес обробки. $[1,4,5]$.

В умовах гідродинамічної кавітації виникає адіабатичне кипіння рідини внаслідок швидкого зниження зовнішнього тиску. За наявності у рідині твердих чи газових включень відбувається утворення, ріст і схлопування бульбашок, що сприяє рівномірному розподілу енергії безпосередньо по всьому об'єму дисперсної частинки і раціональному іiі використанню. Диспергування відбувається в результаті перетворення потенціальної енергії, яка була накопичена бульбашками в стадії їх росту, в кінетичну енергію ударних хвиль при їх схлопуванні. Такий підхід передбачає, що дисипація енергії здійснюється безпосередньо біля дисперсної частинки або на iii поверхні $[4,6]$.

Для дослідження впливу гідродинамічної кавітації на гетерогенні системи був розроблений i змонтований експериментальний стенд (рис. 1). В якості гетерогенної системи для диспергування було обрано водну дисперсію комплексу фосфоліпідів різної концентрації. Стенд працює наступним чином: за допомогою гідравлічного насосу (1) здійснюється циркуляція водно-жирової суспензії під високим тиском (до 0,6 МПа). Витрати i швидкість потоку вимірюється за допомогою електронного ультразвукового витратоміра (3). Тиск до кавітатора (5) i після нього вимірюється за допомо- гою манометрів (4), (6). Температура водної дисперсії в резервуарі (8) вимірюється датчиком температури (7). Даний стенд дозволяє змінювати такі параметри, як робочий тиск рідини та геометричні розміри $\mathrm{i}$ моделі кавітатора i, таким чином, змінювати витрати і швидкість рідини. В даних дослідженнях в якості кавітатора для створення гідродинамічної кавітації використовувалося сопло 3 наступними геометричними розмірами: кут розкриття конфузора $90^{\circ}$, кут розкриття дифузора $120^{\circ}$, діаметр горловини сопла 8 мм i довжина 20 мм.

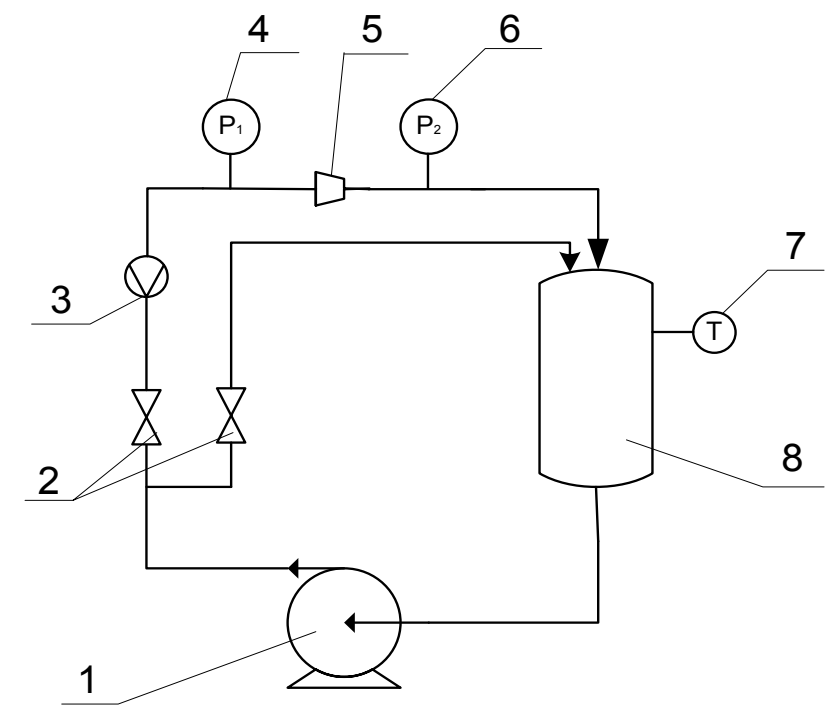

Рис. 1. Схема кавітаційного стенду:

1 - відцентровий насос; 2 - вентиль;

3 - ультразвуковий витратомір;

4, 6-манометр; 5-кавітатор;

7 - датчик температури; 8-резервуар.

В залежності від зміни параметрів проведення процесу і інтенсивності диспергування водної дисперсії фосфоліпідів утворюються ліпідні везикули 3 різними якісними характеристиками. Для визначення раціональних параметрів проведення процесу диспергування водожирової суспензії для утворення фосфоліпідних везикул із заданими властивостями під впливом розвинення гідродинамічної кавітації було досліджено вплив зміни теплофізичних параметрів на діаметр утворених частинок. Діаметр частинок вимірювався методом фотонної кореляційної спектроскопії на лазерному фотон-кореляційному спектрометрі $[7,8]$. 
Першим теплофізичним показником, вплив якого на властивості ліпідних наноструктур, був досліджений - початкова температура матеріалу. Було досліджено зразки 3 початковою температурою матеріалу $20 \pm 2{ }^{\circ} \mathrm{C}, 30 \pm 2{ }^{\circ} \mathrm{C}$ i $40 \pm 2{ }^{\circ} \mathrm{C}$ і концентрацією розчину фосфоліпідів $\mathrm{C}_{0}=0,5 \%$.

Як видно з графіка (рис. 2) середній діаметр частинок у зразків 3 початковою температурою матеріалу $20 \pm 2{ }^{\circ} \mathrm{C}$ i $30 \pm 2{ }^{\circ} \mathrm{C}$ практично не відрізняється при всіх циклах обробки. Проте в результаті обробки зразка 3 початковою температурою $40 \pm 2{ }^{\circ} \mathrm{C}$ середній діаметр частинок вже післ першого циклу диспрегування менший на 100 нм в порівнянні до відповідних значень розмірів інших зразків. Ця залежність зберігається впродовж проведення всього експерименту i при збільшенні інтенсивності обробки за рахунок збільшення циклів диспергування.

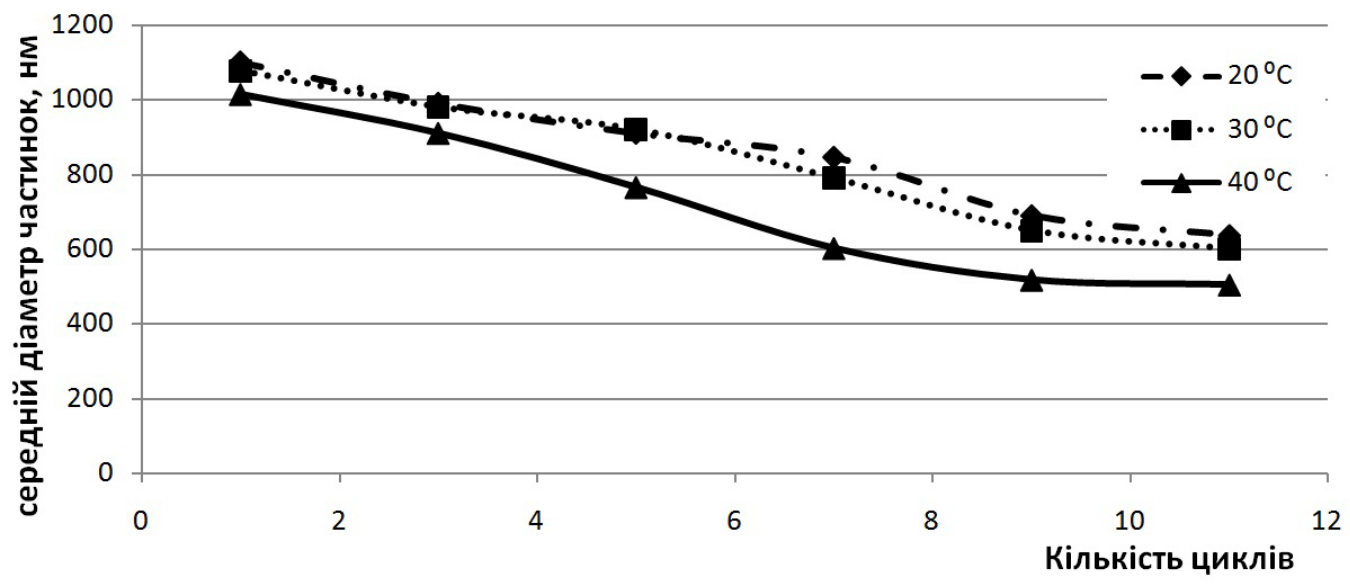

Рис. 2. Вилив початкової температури матеріалу на середній діаметр частинок.

Такий розподіл дисперсності пояснюється природою фосфоліпідів, які відносяться до рідких кристалів. При температурах $20 \pm 2{ }^{\circ} \mathrm{C}$ i $30 \pm 2{ }^{\circ} \mathrm{C}$ використаний нами комплекс фосфоліпідів знаходиться у стані гелю, який при кавітаційній обробці утворює частинки переважно вели- ких розмірів. При температурах $35 \ldots 38{ }^{\circ} \mathrm{C}$ відбувається фазовий перехід системи зі стану гелю в рідкокристалічний стан, що призводить до полегшення умов проведення диспергування, збільшення дисперсності і зменшення діаметру утворених частинок [9].

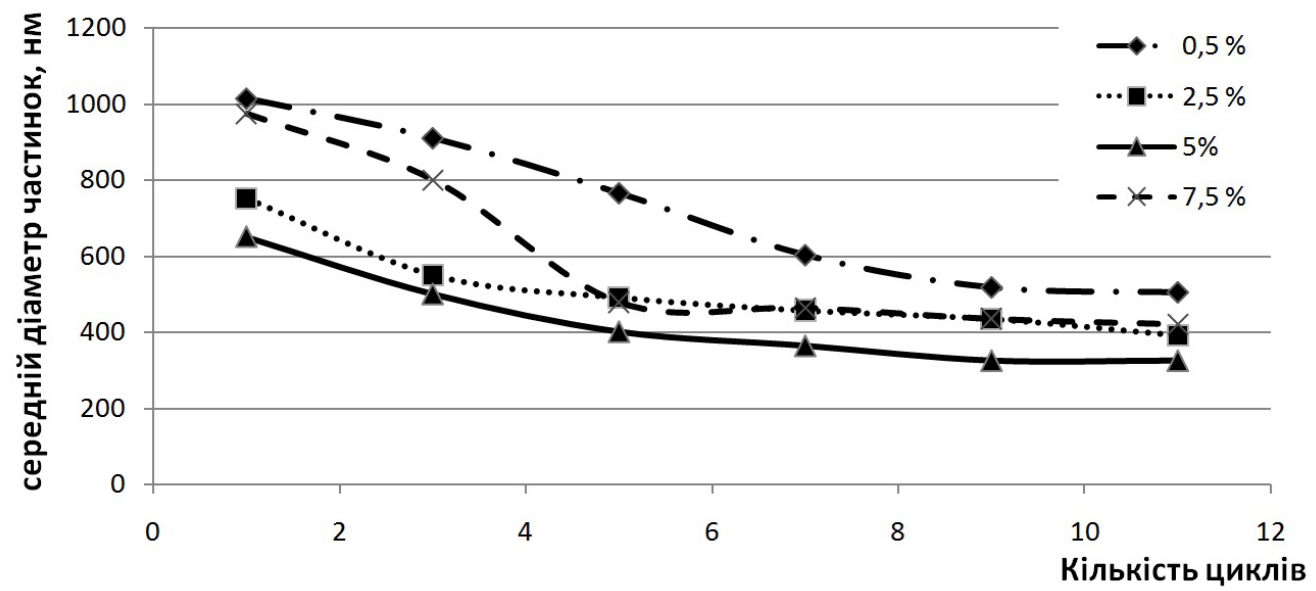

Рис. 3. Вилив концентрації матеріалу на середній діаметр частинок. 
Наступним важливим теплофізичним показником, вПлив якого був досліджений, - концентрація розчину. Було досліджено зразки 3 концентрацією $0,5 \% ; 2,5 \% ; 5,0$ \% і 7,5 \% при температурі $40 \pm 2{ }^{\circ} \mathrm{C}$ (рис. 3).

Як видно з графіка (рис. 3) найкращі умови обробки створюються при диспергуванні зразка 3 концентрацією 5 \% фосфоліпідів. В цьому зразку середній діаметр утворених частинок $\epsilon$ найменшим вже після першого циклу диспергування. Значення середнього діаметру частинок дисперсних систем 3 концентрацією 2,5 i 7,5 \%, оброблених за допомогою гідродинамічної кавітації, наближені між собою, але зразок 3 концентрацією 7,5 \% характеризується високою початковою густиною матеріалу, що погіршує умови диспергування впродовж перших 5 циклів диспергування.

Аналіз одержаних результатів (рис. 2 і рис. 3) показав, що при збільшенні циклічності обробки розмір утворених частинок зменшується після кожного циклу диспергування. Впродовж перших 3...5 циклів диспергування відбувається найбільш суттєве зменшення середнього діаметру частинок в $1,5 \ldots 2$ рази. Подальше збільшення циклів обробки призводить до незначного збільшення дисперсності i ефективність диспергування поступово зменшується.

Важливою характеристикою системи 3 високою дисперсністю $є$ іï стабільність при витримуванні впродовж певного часу. Результати досліджень визначення розподілу частинок дисперсії за розміром в результаті витримування впродовж 7 діб при температурі $4 \pm 0,2{ }^{\circ} \mathrm{C}$ наведені на рис. 4. Як бачимо, дослідні зразки характеризуються високою стабільністю.

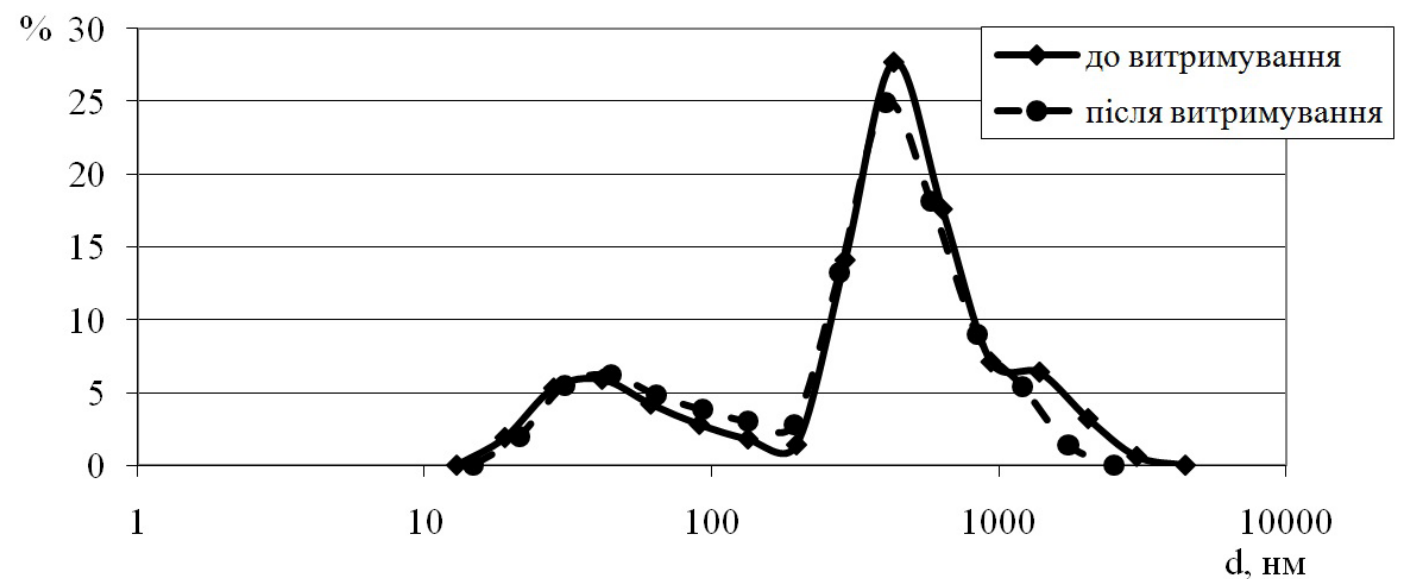

Рис. 4. Розподіл дисперсності частинок за розмірами дослідних зразків безпосередньо після обробки і після 7 діб зберігання в охолодженому стані.

Висновки

Дослідження показали високу ефективність використання гідродинамічної кавітації при обробці складних гетерогенних систем для отримання ліпідних наноструктур. Комплекс проведених досліджень дозволив визначити раціональні тепло-технологічні режими i параметри утворення фосфоліпідних наноструктур за допомогою кавітаційної обробки при обраному типі кавітатора. Дослідження показали високу стабільність утвореної системи, що підтверджує високу ефективність запропонованої обробки.

\section{ЛІТЕРАТУРА}

1. Долинский А.А. Тепломассообмен и гидродинамика в парожидкостных дисперсных средах/ А.А. Долинский, Г.К. Иваницкий.- К.: Наукова думка, 2008. - 382 с. 
2. Долинский A.A. Дискретно-импульсный ввод энергии в теплотехнологиях/А.А. Долинский, Б.И. Басок, И.С. Гулый, А.И. Накорчевский, Ю.А. Шурчкова.- К.: Наукова думка, 1996. $208 \mathrm{c}$.

3. Федоткин И.М. Кавитация, кавитационная техника и технология, их использование в промишлености (теория, расчеты и конструкции кавитационных аппаратов). Ч.І/ И.М. Федоткин, И.С. Гулый. - К.: Полиграфкнига, 1997. - 838 с.

4. Вітенько T.M. Гідродинамічна кавітація у масообмінних, хімічних і біологічних процесах/ Т.М. Вітенько. - Тернопіль: ТДТУ ім. І.Пулюя, 2009. - 220 c.

5. Кнэпn Р. Кавитация /Кнэпп Р., Дейли Дж., Хэммит Ф. - М.: Мир, 1974. - 687 с.
6. Кулагин B.A. Перспектива развития кавитационных нанотехнологий / В.А. КулагинФГОУ ВПО « Сибирский федеральный университет»-2010, - C 48-51.

7. Yegin B. Lipid nanocapsule size analysis by hydrodynamic chromatography and photon correlation spectroscopy // Yegin B., Lamprecht A. - International Journal of Pharmaceutics, 2006. № 320. - P. 165-170.

8. Henk G. Merkus. Particle Size Measurements. Fundamentals, Practice, Quality. - Springer, 2009. $533 \mathrm{p}$.

9. Геннис P. Биомембраны. Молекулярная структура и функции : пер. с англ. / Р. Геннис. М.: Мир, 1997. - 597 с. 


\section{PHENOMENON OF HYDRODYNAMIC CAVITATION AS AN EFFECTIVE DISPERSION MECHANISM WHEN REALIZATION OF DISCRETE-PULSE ENERGY INPUT}

\section{Dolinsky A.A., Avdeeva L.Y., Zhukotskyy E.K., Makarenko A.A.}

Institute of Engineering Thermophysics of the National Academy of Sciences of Ukraine, st. Zhelyabova, 2a, Kyiv, 03680, Ukraine

The cavitation's influence on the intensification of the dispersing process at the realization of mechanisms of DPEI are considered. The article deals with the main existing methods for creating cavitation. Designed and installed an experimental stand for research of the influence of the hydrodynamic cavitation on dispersion of complex heterogeneous systems. Given results of experimental researches of influence of thermal modes of dispersion systems with phospholipids on the properties of formed systems. Also, the paper presents the results of studies of determining the distribution of particle dispersion by size as a result of holding its for 7 days in refrigerated conditions. The results showed high stability of the formed system. Conclusions regarding rational technological modes of operation are made.

References 9, images 4.

Key words: hydrodynamic cavitation, phospholipids, discrete pulse energy input

1. Dolinsky A.A. Heat and mass transfer and hydrodynamics in the vapor-liquid dispersion environments / A.A.Dolynskyy, G.K. Ivanitsky. Kyiv: Naukova Dumka, 2008. - 382 p.

2. Dolynskyy A.A. Discrete-pulse energy into heat technologies / A.A. Dolynskyy, B.I. Basok, I.S. Guly, AI Nakorchevskii, Y. Shurchkova. -Kyiv: Naukova Dumka, 1996. - 208 p.

3. Fedotkin I.M. Cavitation cavitation technique and technology, their use in industry (theory, calculations and designs cavitation devices). CH.I / I.M. Fedotkin, I.S. Guly. - K .: Poligrafkniga, 1997. $-838 \mathrm{p}$.

4. Vitenko T.M. Hydrodynamic cavitation in mass transfer, chemical and biological processes / T.M. Vitenko.-Ternopil: TDTU im.I.Pulyuya, 2009. -220 p.

5. Knерp R. Cavitation / Knэpp R., Dale, J., Hemmyt F. - Moscow: Mir, 1974. - 687 p.

6. Kulahyn V.A. The prospect of development of cavitation nanotechnology / Kulahyn V.A. - FSEI HPE "Siberian Federal University" - 2010 - M 4851.

7. Yegin B. Lipid nanocapsule size analysis by hydrodynamic chromatography and photon correlation spectroscopy // Yegin B., Lamprecht A. - International Journal of Pharmaceutics, 2006. - № 320. - P. 165-170.

8. Henk G. Particle Size Measurements. Fundamentals, Practice, Quality / Henk G., Merkus. - Springer, 2009. - 533 p.

9. R. Gennis Biomembranes. The molecular structure and functions: lane. from English. / R. Gennis. - M .: Mir, 1997. - 597 p.

Получено 14.09.2015

Received 14.09.2015 